\title{
Experimental Study of Actual Operation of Plastic Tube Concrete Constructions
}

\author{
Alexandr Dolzhenko \\ Department of municipal cadaster and engineering \\ investigations \\ Belgorod State Technological University named after V.G. \\ Shoukhov \\ Belgorod, Russia

\section{Andrey Naumov} \\ Department of expertise and property management \\ Belgorod State Technological University named after V.G. \\ Shoukhov \\ Belgorod, Russia
}

\author{
Andrey Shevchenko \\ Department of municipal cadaster and engineering \\ investigations
}

Belgorod State Technological University named after V.G. Shoukhov

Belgorod, Russia

Karina Kara

Department of municipal cadaster and engineering investigations

Belgorod State Technological University named after V.G. Shoukhov

Belgorod, Russia

karina200386@yandex.ru

\begin{abstract}
The paper presents practical aspects of experimental research and numerical modeling of stress-strain parameters of the proposed construction element - plastic tube concrete (PTC). The obtained experimental data indicating the loss of load-bearing capacity enabled one to perform finite element analysis and to examine equivalent stresses in the middle sections of the simulated specimens through Mohr theory. The resulting numerical dependences are well conformed with the experimental data and make it possible to give a calculated justification for the experimentally proven increase in the loadbearing capacity of a PTC structure with respect to a nonencased concrete structure. The established load-bearing capacity coupled with the low cost and availability of plastic tubes makes it possible to consider PTC as an effective construction approach for some elements of building framing erected in record-breaking time, in restricted construction areas and along with other obstacles complicating traditional concretebased building technology.
\end{abstract}

Keywords - plastic tube concrete, tube concrete, polythene pipes, frame house building

\section{INTRODUCTION}

Individual housing construction requires the use of inexpensive efficient construction technologies that allow the erection of vertical frame structures of buildings with minimal machine costs and time scales. At the same time, in the constructions of private houses, the loads created by the external environment are relatively small and have a wellpredictable behavior. In these respect, a suitable constructive solution applied to vertical framings is tube concrete (TC).

It is common to use structural components consisting of steel tubes filled with concrete in building structures that mainly work in compression. Since such building structures were first mentioned in the 1930s, a number of studies have been carried out to understand how these structural elements work. All these studies resulted in a number of scientific discoveries, among which there is the phenomenon of increasing the strength of concrete in a tube and negative shrinkage $[1,2]$.
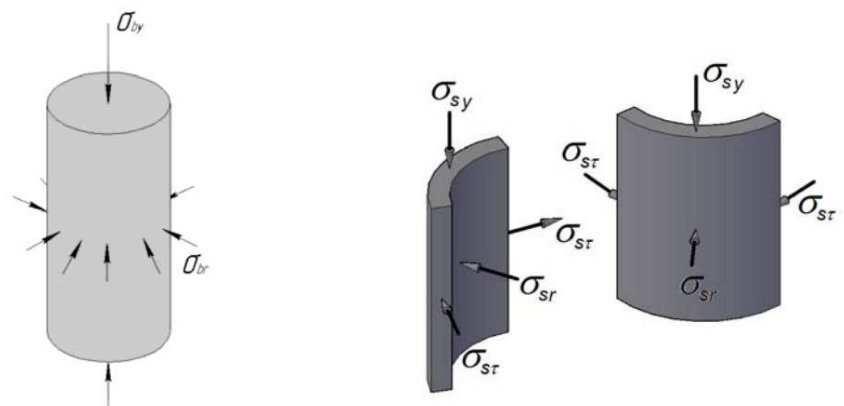

Fig. 1. Stress state of concrete core and encasement

Having analyzed many precedent experiments, it is possible to highlight the following main features of strainstress behavior of TC structures:

- The concrete core is under volumetric compression (Fig. $1)$.

- The encasement operates under conditions of a complex 'compression-stretching-compression' stress state (Fig. 1).

- The lateral pressure magnitude of the concrete core on encasement $\sigma_{\mathrm{br}}$ insignificantly depends on the ratio of transverse strain coefficients of the concrete and the encasement due to the low elasticity of the encasement in comparison with that of the concrete.

- The joint work of the concrete core and the encasement continues up to PTC failure.

- The direction of symmetry axes of compressed PTC elements coincides with the directions of normals of main sites (the slope angle of Chernov-Lüders lines is determined similarly with the angle of the steel encasement surface in the theory of steel concrete calculation). 
- The distribution of longitudinal deformations along the cross-section of TC structures during off-axis compression shows that it is possible to use the hypothesis of plane cross sections.

Other advantages of TC structures include cost effectiveness (less weight, less labor, less cost compared to concrete structures) and increased flexural rigidity [3]. The shortcomings include insufficient research as to how the construction behaves under off-axis compression, creep and shrinkage of concrete in a tube, the change in the controlled parameters of the structure over time. Some other disadvantages should be attributed to a large divergence in controlled parameters that occurs when sealing the concrete mixture manually. However, the latest studies show the swelling of concrete in a tube instead of its previously expected shrinkage, which undoubtedly has a positive effect on the concrete property.

In addition, the use of unprotected metal in high humidity or aggressive environments makes it difficult to operate TC building structures. The thickness of the tube, taking into account its decrease over time, has to be overdesigned (in excess) which reduces the cost effectiveness of this type of building structures. Besides, costs incurred to ensure constant repair of the tube protective coating are significant.

With that in mind and assuming that the use of a metal tube at low loads is not appropriate, the authors proposed using a plastic (polymer) tube as an encasement and further considered the actual operating conditions and stress-strain parameters of the proposed construction, specifically PTC.

Two types of plastics were used as a PTC encasement, namely, polypropylene and polyethylene that are the most widely applied to produce tubes with a diameter of more than $100 \mathrm{~mm}$.

The advantages of plastics include:

- universal chemical and corrosion resistance;

- strength and elasticity;

- easy coloration process;

- lower thermal conductivity compared with metals.

The disadvantages include:

- decrease in heat resistance;

- flammability;

- aging from ultraviolet rays;

- large (8 times more than steel) coefficient of temperature expansion.

To conduct initial testing of short specimens of structures from a plastic tube filled with concrete, 9 specimens were made: 3 - in a polyethylene tube formwork, 3 - in a polypropylene tube formwork and 3 - in a formwork that was dismantled on the second day (Fig. 2).

Specimens with an outer diameter of $110 \mathrm{~mm}$ and a height of $400 \mathrm{~mm}$ were filled with heavy B15 concrete and were sealed by hand-ramming with bars longer than the length of the tube. The entire height of the tube was divided into 10 layers of concrete, each of which was rammed. The number of bar plunges was no less than one per $10 \mathrm{~cm}^{2}$ of the sealed concrete surface. When sealing, the removal of air and water from the concrete mixture was observed.

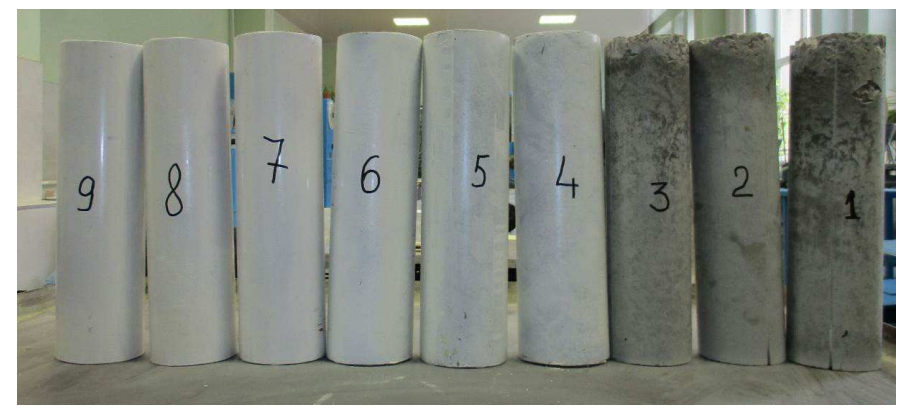

Fig. 2. Specimens of STCC structures in a plastic tube: 1-3 - unencased specimens; 4-6 - specimens in a polyethylene encasement; 7-9 specimens in a polypropylene encasement

The analysis of the specimens after destruction (Fig. 3) showed that the monolithic nature of concrete was extremely high. In addition to this, microstructural studies of hardened cement paste using Quanta 200 3D scanning electron microscope with Pegasus 2000 integrated system confirmed the effectiveness of the concrete ramming method.

Many researchers [ 4 ... 7] believe that physical and mechanical properties of hardened cement paste directly depend on the composition and degree of crystallineness of hydrated newgrowths and cells that characterize the microstructure of hardened material. Therefore, the study of concrete microstructures sealed in various ways is of considerable scientific and practical interest.

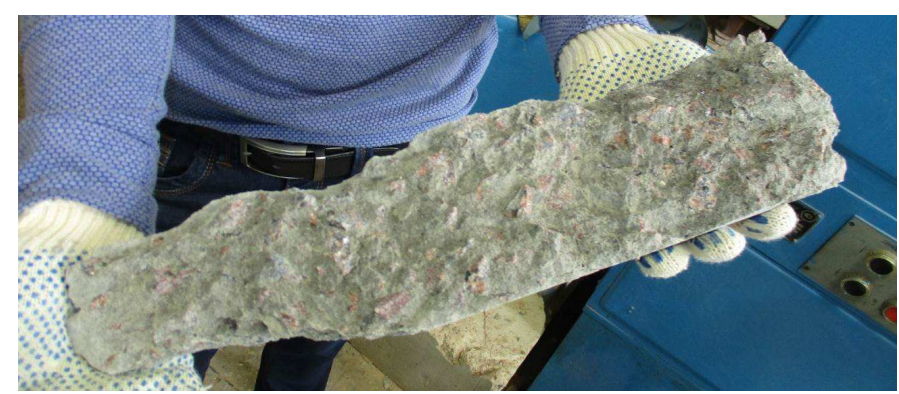

Fig. 3. Monolithic nature of concrete in tested specimens

After 28 days, the specimens were tested for central compression on a hydraulic press (Fig. 4). To control the strength of concrete in tubes, standard cubic specimens with dimensions of $100 \times 100 \mathrm{~mm}$ and $70 \times 70 \mathrm{~mm}$ were additionally tested.

The tests showed that concrete cylinders are destructed as per the classical scheme (crushing of pier-side areas and longitudinal cracks height), while the strength of PTC in the polyethylene encasement is higher than cubic by up to $35 \%$, and in the polypropylene encasement - up to $15 \%$ (Table 1). 


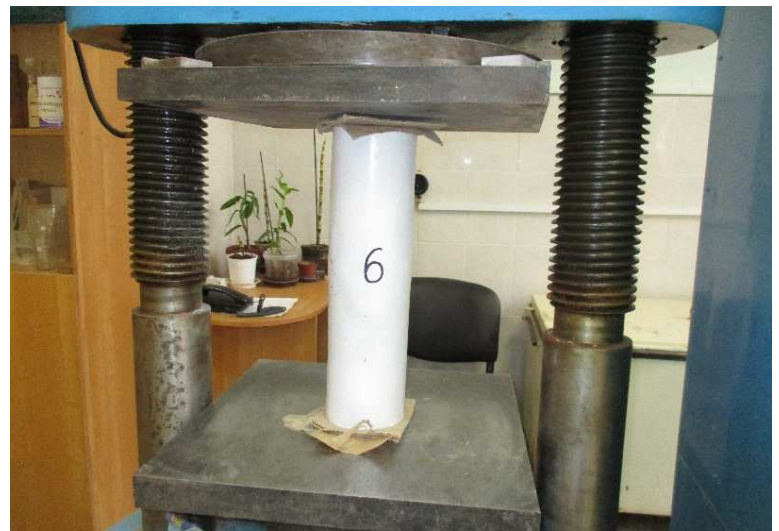

Fig. 4. Specimen of a short TC bar before testing

TABLE I. PHYSICAL AND MECHANICAL PROPERTIES OF TC STRUCTURES IN A PLASTIC TUBE

\begin{tabular}{|c|c|c|}
\hline No. & Ultimate breaking load, tf & Average breaking load, tf \\
\hline 1 & 12.25 & \multirow{2}{*}{10.9} \\
\hline 2 & 9.75 & \\
\hline 3 & 10.75 & \multirow{2}{*}{14.7} \\
\hline 4 & 16.5 & \multirow{2}{*}{12.5} \\
\hline 5 & 11.25 & \multirow{2}{*}{12.5} \\
\hline 6 & 16.25 & \\
\hline 7 & 12.75 & \\
\hline 8 & 12.5 & \\
\hline 9 & 12.25 & \\
\hline
\end{tabular}

It is reasonable to determine the increased strength of PTC by implementing the above mentioned effect in a mathematical model that is calculated through the finite element method ensured by specialized software. The paper presents the design of TC cylinder specimen with a size of 400 $\times 110 \mathrm{~mm}$ in a polyethylene tube having a wall thickness of 5 $\mathrm{mm}$.

The design strength of a PTC structure is the strength property of the materials, i.e. plastic and concrete, that make up the composite structure. Considering the joint work of the construction materials while taking no account of the specific features of the materials, technological production factors, actual conditions of tube-concrete contact, as per the schemes used to design concrete-filled steel tubes, leads to some significant deviations in the design strength from experimentally proven resistances of the structure. In this regard, it is relevant to design PTC by creating an analytical apparatus that deals with the strength, stress-strain, and geometric characteristics of PTC materials. Since the strength and stress-strain characteristics of concrete are well studied and widely used in applied calculation methods [9], the paper presents experimental data on the ceiling values and behavior of physical and mechanical properties of plastics under the load, which can further be adopted to create an engineering methodology for designing PTC.

The authors propose the technique for the analytical determination of stress-strain parameters of PTC components, namely concrete core and polymer encasement, based on the assumptions that until the ultimate limit state occurs (failure, significant deformations, loss of stability of the whole element or its encasement), the concrete core and the plastic tube work together.
In the longitudinal direction, the concrete core experiences axial compression and the main stresses appear in the cross-section, as follows:

$$
\sigma_{3}=\frac{N}{A} .
$$

The transverse strains of the core will create the internal pressure $p$ that stretches the plastic tube. In this case, the tube also exerts compressive pressure of the same magnitude on the concrete core and the other two main stresses in the concrete will have the following values:

$$
\sigma_{1}=\sigma_{2}=-p
$$

As the ratio of the tube wall to the radius is sufficiently small - 1/30 or less, it can be regarded as a shell.

Circular stresses in a cylindrical encasement is

$$
\sigma_{k}=\frac{p d}{2 t},
$$

where $d$ is the internal diameter of the tube, $t$ is the thickness of the tube wall.

Then,

$$
p=\frac{2 t \sigma_{k}}{d} .
$$

The frictional forces between the concrete and the tube were not taken into account, hence the meridional stresses were assumed to be zero and the tube experiences a linear stress state.

To determine the value of $p$, the relative deformations of the concrete were expressed by the following dependences:

$$
\varepsilon_{2}=\frac{1}{E_{b}}\left(\sigma_{2}-\mu\left(\sigma_{3}+\sigma_{1}\right)\right)=\frac{1}{E_{b}}\left(-p-\mu\left(\sigma_{3}-p\right)\right),
$$

which are equal to the tube expansion deformation:

$$
\varepsilon_{r}=\frac{\sigma_{k}}{E_{p}}=\frac{p d}{2 t E_{p}}
$$

or

$$
\frac{1}{E_{b}}\left(-p-\mu\left(\sigma_{s}-p\right)\right)=\frac{p d}{2 t E_{p}} .
$$

The solution of this equation for $p$ is

$$
p=\frac{\mu \sigma_{s}}{\left(\frac{d E_{b}}{2 t E_{p}}\right)-\mu+1}=\frac{\mu\left(\frac{N}{A}\right)}{\left(\frac{d E_{b}}{2 t E_{p}}\right)-\mu+1} .
$$

In order to study the type and nature of the physical nonlinearity of PTC plastics deformation, the authors experimentally determined the stress-strain characteristics of polyethylene used in PTC tubes on the universal hydraulic testing machine WEW-600D. The longitudinal and transverse strains were measured automatically with a $0.01 \%$ load step. The results of the tests are shown in Fig. 5. 


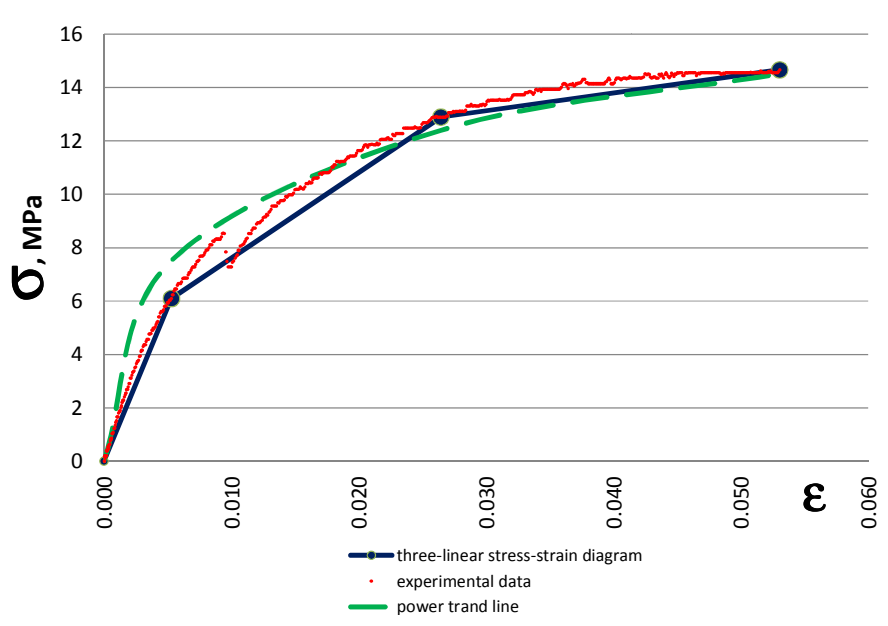

Fig. 5. PTC plastics stress-strain diagram (experimental data obtained by the authors)

It was experimentally proved that with the increased loading, PTC plastics demonstrate a significant physical nonlinearity of stress-strain properties. The stress-strain modulus $E$ falls from 1200 to $280 \mathrm{mPa}$ with the increase in stresses from $0.1 \%$ to $100 \%$ of the ultimate breaking load, while the transverse strain coefficient $\mu$ remains in the range $0.3-0.35$. These results are consistent with those obtained by tube manufacturers who established similar characteristics of materials used in PTC encasements [11].

The PTC plastics stress-strain diagram is well approximated by the power function $Y=a_{2} X^{b 2}+a_{1} X+a_{0}$, from which coefficients $a_{2}=863 ; b_{2}=0.85 ; a_{1}=-499$; $a_{0}=-0.99$ were calculated, with the determination coefficient $R^{2}=0.997$.

The paper presents PTC numerical models that are comprised of exponential stress-strain diagram built in the software application Lira 9.6, and a three-linear piecewise continuous diagram of plastic deformation, based on the experimental studies (Fig.5).

In order to quantify the effect of physical and mechanical characteristics of PTC materials on the stress-strain behavior of the structure under central compression, the performance of a cylindrical PTC prism with a diameter of 110 and a height of $400 \mathrm{~mm}$ was simulated using the finite element method in stresses in Lira 9.6. Strength and stress-strain characteristics of the concrete were taken in accordance with the law included in program 21 (exponential normative strength), plastic tube according to law 14 (piecewise linear deformation law).

The problem was solved in a volumetric nonlinear formulation for finite elements: plastic encasement plates $17 \times 10 \times 5 \mathrm{~mm}$ (FE No. 244 referred to as physically nonlinear universal quadrangular encasement FE) and bulk elements of the concrete core (FE No. 233 referred to as physically nonlinear trihedral prism) with sizes $11 \times 13 \times 10 \mathrm{~mm}$ (Fig. 6). The movements of the upper nodes were combined to simulate a low-deformative press cushion. The center-point load in 116 upper nodes was $1.28 \mathrm{kN}$, which corresponded to a load of $150 \mathrm{kN}$ that destroyed the reference concrete prism specimen.

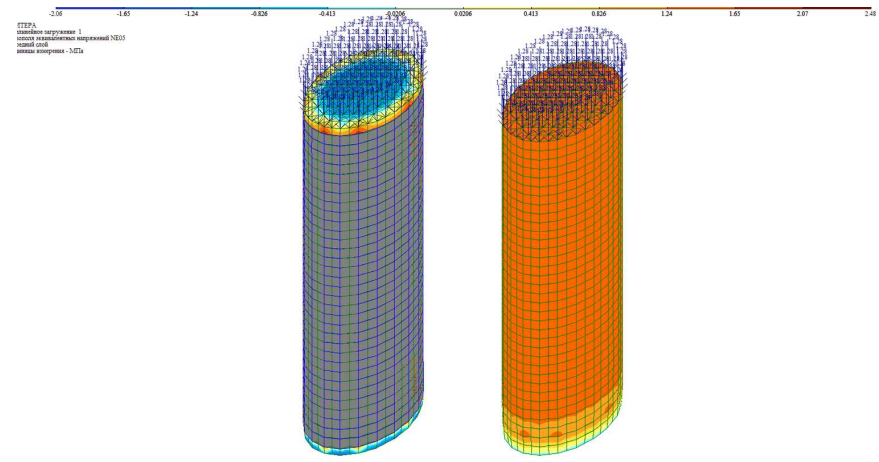

Fig. 6. Finite element model of the tested PTC specimen (the reference unenceased prism of the same concrete type and dimensions is on the right)

The main stresses arising in the middle sections of the simulated PTC specimens and the test non-encased concrete cylinder are shown in Fig. 7. The obtained values of $\sigma_{1}=0.7$ $\mathrm{mPa}$ in both specimens are less than the normative strength of B15 concrete for uniaxial tension $\left(R_{b t n}=1.1 \mathrm{mP}\right)$, while $\sigma_{3}=$ $12.8 \mathrm{mP}$ in the test cylinder is greater than the normative strength B15concrete for uniaxial compression $\left(R_{b t n}=11 \mathrm{mPa}\right)$ [17].

Considering the main stresses separately does not explain all possible causes of the material failure used in the test specimen. As a consequence, analyzing the modeling results the authors focused mainly on the stresses equivalent to uniaxial tensile stress in finite elements. It is assumed that if equivalent stresses $\sigma_{\mathrm{e}}>\mathrm{R}_{\mathrm{btn}}$ appear in the sections of the concrete specimen, cracks are formed resulting in the subsequent material failure. Accordingly, if equivalent stresses exceed the design concrete tensile strength, it indicates the formation and development of destructive processes in the material and the exhaustion of load capacity of the test specimen as per the ultimate limit state.

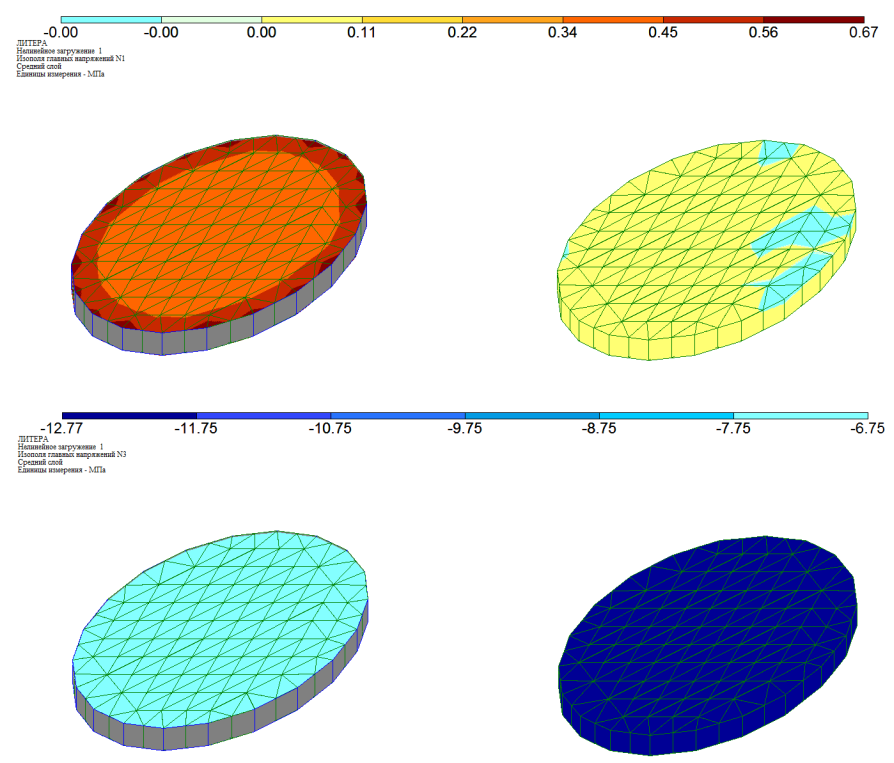

Fig. 7. Main stresses $\left(\sigma_{1}-\right.$ at the top and $\sigma_{3}-$ at the bottom), arising in the middle section of simulated specimens being destructed 
As noted in [8], it is reasonable to use Mohr theory to determine equivalent stresses $\sigma_{\mathrm{e}}$ in concrete cubes and prisms. What is more, equivalent stresses in prisms determined by the theory for the state at which cracks are formed in concrete correspond to the tensile strength. This is quite convenient for analyzing strain-stress behavior of PTC concrete core that is a concrete cylinder of a certain class and the design concrete tensile strength.

Mohr strength theory does not contain any criterial hypothesis and consists in establishing a definite dependency of the strength properties on the type of the stress state of a material [10]. The stress state is generally characterized by the greatest tangential stress and the normal stress with the latter being displayed on the area where the former is effective. The yield condition is determined by the envelope of large stress circles (Mohr's circles) for the limit stress states. The influence of the mean stress $\sigma_{2}$ is not taken into account. Flowability occurs when a large circle of stresses for the stress state under consideration touches this envelope (Fig. 8).
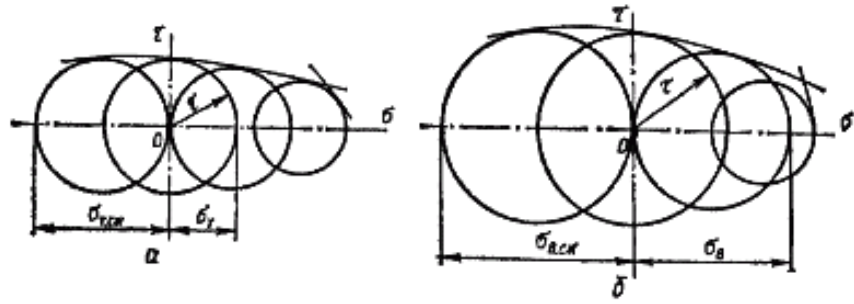

Fig. 8. Mohr circles

For brittle materials with different tensile and compressive strengths, the failure condition is determined according to Mohr theory, i.e. the envelope of the limit stress circles corresponds to failure (Fig. 8). In this case, the corresponding stresses under the volumetric stress look like:

$$
\sigma_{t}=b \times \sigma_{\mathrm{br}}-\sigma_{\mathrm{by}}
$$

where $b=\mathrm{R}_{\mathrm{b}} / \mathrm{R}_{\mathrm{bt}}$, and Mohr strength condition looks like:

$$
\sigma_{t} \leq[\sigma] .
$$

The design outcomes of equivalent stresses in accordance with Mohr theory for the study PTC specimen in a polyethylene encasement $5 \mathrm{~mm}$ thick and a test specimen of a non-encased concrete cylinder made of the same concrete are shown in Fig. 9.
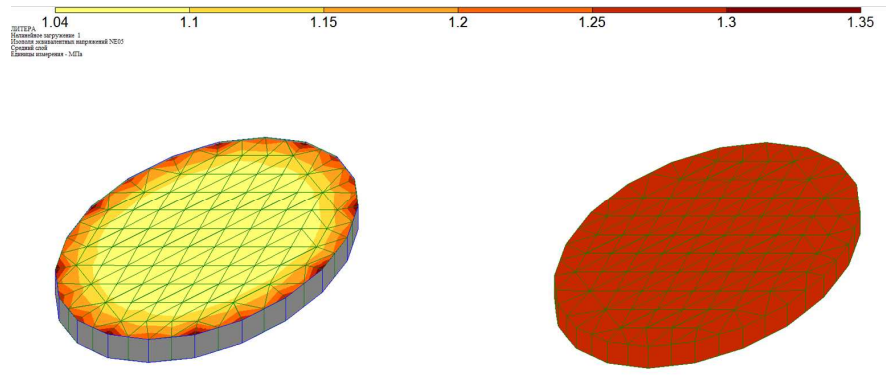

Fig. 9. Equivalent stresses $\sigma_{\mathrm{e}}$ in the middle prism section as per Mohr theory: study PTC concrete core - on the left; cylinder concrete test non-encased specimen - on the right
Equivalent stresses corresponding to the state of the test specimen failure were $1.35 \mathrm{mPa}$, which is higher than $\mathrm{R}_{\mathrm{btn}}$ of B15 concrete. Equivalent stresses typical of the most part of PTC specimen were $1.0 \mathrm{mPa}$, which is less than $\mathrm{R}_{\mathrm{btn}}$ and thus enables one to estimate PTC load capacity reserve in comparison with non-encased specimens up to $25 \%$ and is well conformed with the experimental data of the authors.

According to the results of the numerical experiment, the change in the value of transverse strain of the plastic encasement in the limits of 0.3 to 0.4 (up to $33 \%$ ) does not significantly affect the stress-strain state of the PTC concrete core under load.

The determined relative decrease in the equivalent stresses of PTC that entails an increase in its load capacity with respect to a purely concrete structure is due to the redistribution of stresses in PTC elements during their joint operation. The discovered reserve to increase the PTC load capacity makes it possible to load its concrete core in a more rational way. Taking into account the low cost of a polymer tube, the use of PTC is a cost effective alternative to traditional structural solutions applied to frame elements in low-rise housing construction.

\section{Acknowledgment}

The work was carried out in the framework of the Program of flagship university development on the base of Belgorod State Technological University named after V.G. Shoukhov, using equipment of the High Technology Center at BSTU named after V.G. Shoukhov.

\section{References}

[1] A.A. Dolzhenko, "Shrinkage of Concrete in a Tubular Clip", Concrete and Reinforced, №8, 1960.

[2] A.E. Lopatto, "On the properties of concrete, hardened at the locked clips", Building materials and construction, №4, 1964.

[3] A.I. Kikin, RS Sanzharovsky, V.A. Truval, Structures of steel pipes filled with concrete, M., Stroyizdat, 1974, p. 144.

[4] J. Shtark, B. Mezer, "Study of hydration of Portland cement using scanning electron microscopy", Cement and its application, № 3, pp. 49-53, 2006.

[5] Hui Li, Hui-gang Xiao, Jie Yuan, Jinping Ou, "Microstructure of cement mortar with nano-partioles", Composit B, № 2, pp. 185-189, 2004.

[6] Feng Qi, Ba Hengjing, Fan Zhengyl, Yang Ying Gao Xaojian, "The study of the microstructure at the interface in the early period of hardening of cement with fine dispersible fillers", Fuhe Cailioa xuebau Acta Mater. Compos. Sin, № 4, pp. 72-76, 2003.

[7] Middendorf, B. "Makro-Mikro-Nano-Nanotechnologie fur die Bindemined und Betonentwicklung", Betonwerk-Fertigteil-Techn, № 2, pp. 18-19, 2005.

[8] Yu.V. Krasnoshchekov, R.A. Galuzina, "Strength of concrete as resistance to destruction", Bulletin of SibADI, Issue 1 (47), pp. 61-65, 2016.

[9] SP 63.13330.2012

[10] S.P. Fesik, Handbook on the resistance of materials, 2 nd ed., p. 280 , 1982.

[11] http://www.gidroplast.ru/dictionary-truby/tekhnicheskie_truby_pnd/

[12] A.V. Shevchenko, A.E. Naumov, A.V. Dolzhenko, "Effective Pipeline Concrete Structures for Individual Housing Construction", Economics, Science, and Production: Proceedings No. 28. Moscow: Publishing House "Moscow State Machine-Building University (MSMBU)", pp. 40-42, 2015. 
[13] A.V. Shevchenko, A.V. Dolzhenko, A.E. Naumov, "Investigation of the strength of tube-concrete in plastic tubes for central compression", Current Issues in Education and Science: proceedings of the international scientific and practical conference. Part 4. Tambov: Consulting company Ucom, Ltd., pp 172-175, 2015. [International Scientific and Practical Conference "Current Issues in Education and Science", p. 210, 2015].

[14] Eurocode 4. Designing of steel-reinforced concrete structures. General rules for buildings, Transl. from German. Poltava: PSTU, p. 180, 1997.

[15] I.R. Gray, E.V. Chernyshova, "Steel-concrete in modern construction", Science-intensive technologies and innovations: Jubilee International scientific-practical conference dedicated to the 60th anniversary of BSTU named after V.G. Shukhova, XXI scientific readings. Belgorod State Technological University named after V.G. Shukhova, 2014, pp.
112-115 [Jubilee International Scientific and Practical Conference, dedicated to the 60th anniversary of BSTU named after V.G. Shukhova " Science-intensive technologies and innovations ", p. 265, 2014].

[16] I.R. Gray, Stress-strain state of reinforced concrete beams of rectangular cross-section with a composite clip under compression and bending, dis. cand. tech. sciences. Belgorod, p. 159, 2000.

[17] L.K. Luksha, Strength of tube-concrete. Minsk: High, 1977.

[18] P. S. Sanzharovsky, Theory and calculation of the strength and stability of structural elements from steel tubes filled with concrete.

[19] V.A. Kataev, "Theoretical study and calculation of tube -concrete rods ", Concrete and Reinforced Concrete, №2, pp. 26-28, 1993.

[20] G.V. Nesvetaev, I.V. Rezvan, "Evaluation of the strength of tubeconcrete", Fundamental research, № 12-3, pp. 580-583, 2011. 